\title{
New Cementitious Materials Based on Alkali-Activated Fly Ash: Performance at High Temperatures
}

\author{
Ana Fernández-Jiménez ${ }^{\dagger}$ and Angel Palomo \\ Instituto de Ciencias de la Construcción Eduardo Torroja (CSIC), Serrano Galvache 4, 28033 Madrid, Spain \\ José Y. Pastor and Antonia Martín \\ Department of Materials Science, Polytechnic University of Madrid, E28040 Madrid, Spain
}

\begin{abstract}
This paper reports on a comparative study of the mechanical performance at different temperatures of a commercial Portland cement, used as a control, and a new cementitious material made from an 8M-NaOH activated fly ash and containing no OPC. Two types of mechanical tests were conducted: (i) high temperature mechanical tests, to determine the strength and fracture toughness of the two materials between $25^{\circ}$ and $600^{\circ} \mathrm{C}$, and (ii) post-thermal treatment tests, to evaluate the residual strength after $1 \mathrm{~h}$ of exposure to different temperatures $\left(200^{\circ}\right.$, $400^{\circ}, 600^{\circ}, 800^{\circ}$, and $1000^{\circ} \mathrm{C}$ ). In both cases, the results showed that the new cementitious material performed significantly better at high temperatures than the Portland cement control. Differential thermogravimetry (DTG)/TG, Fourier transform infrared (FTIR), and X-ray diffraction analyses were also conducted to analyze the mineralogical and microstructural variations taking place in the material as a result of high temperature exposure. The results of these tests were correlated with the mechanical behaviour observed.
\end{abstract}

\section{Introduction}

$\mathrm{P}$ ORTLAND cement is unquestionably the primary cementitious material used in construction nowadays, and the production of vast amounts of Portland cement occasionally results in environmental problems in terms of energy consumption as well as pollution. Indeed, with the manufacture of one tonne of cement approximately 0.8 tonnes of $\mathrm{CO}_{2}$ are launched into the atmosphere. This contributes substantially to global air pollution, for the cement industry accounts for $5-8 \%$ of worldwide $\mathrm{CO}_{2}$ emissions. ${ }^{1}$ In particular, the Spanish cement industry's $\mathrm{CO}_{2}$ emissions grew by $28.5 \%$ between 1990 and 2002, compared with the target growth of $15 \% . \mathrm{CO}_{2}$ emissions continued rising between 2002 and 2007. With the mounting pressure to reduce energy demands and polluting gas emissions in all industrial processes in this globally interconnected world, the cement industry has come under the scrutiny of environmental policy makers.

Moreover, concrete made from Portland cement is subject to certain durability problems that are difficult to solve (sulphate attack, reinforcement corrosion, aggregate-alkali reaction and so forth). All the foregoing makes the pursuit of alternative cementitious materials able to reduce $\mathrm{CO}_{2}$ emissions and improve on some of the shortcomings present in Portland cement, one of the scientific community's primary objectives.

In this same vain, around one billion tonnes of fly ash are produced annually world-wide in coal-fired steam power plants. $^{2-4}$ In the best-case scenario this waste is stockpiled, but more often than not it is simply dumped. In either case, it constitutes a serious environmental and economic problem for which a solution is yet to be found.

One option to eliminate this ash in an ecologically sensitive manner is to reuse it. The alkali activation of aluminosilica materials is a chemical process that transforms partially or wholly vitreous structures into compact cementitious skeletons. The main reaction product obtained is an alkaline aluminosilicate that has previously been described as a zeolite precursor. ${ }^{5-7}$ Because of the long- and medium-range disorder of its three-dimensional structure, this aluminosilicate is mesoscopically amorphous and therefore is not accessible to X-ray diffraction analysis. NMR studies ${ }^{6,7}$ have shown that on the nanoscopic scale, this gel in fact has a three-dimensional structure in which the $\mathrm{Si}$ is found in a variety of environments, with a predominance of $\mathrm{Q}^{4}(3 \mathrm{Al})$ and $\mathrm{Q}^{4}(2 \mathrm{Al})$ units. Different types of zeolites (hydroxysodalite, Na-chabazite, zeolite $\mathrm{P}$ and so on) are usually obtained as secondary reaction products. The amount and type of such zeolites depends on the nature of the alkaline activator used and the curing conditions.

As per the most recent research on the properties that best define these cements, these systems can attain compressive strengths of over $60 \mathrm{MPa}$ after brief thermal curing. ${ }^{8,9}$ In addition, the resulting material is highly durable and particularly resistant to aggressive acids, the aggregate-alkali reaction and so on. ${ }^{10,11}$ Moreover, this material performs better than Portland cement mortars in other respects as well, such as shrinkage and matrix-reinforcement steel bonding. ${ }^{12}$ These materials are likewise well suited to fix toxic elements. ${ }^{13-17}$ and protect the steel reinforcement from corrosion processes. ${ }^{18}$

At the same time, construction materials are subject to increasingly stricter fire resistance requirements in safety regulations (see the Spanish Technical Building Code [CTE DB_SI March 2006], Spanish standard UNE-23727, and Spanish and international standard UNE-EN.ISO 11925). In order to appropriately evaluate the impact of accidental exposure to fire on standing structures, the response of these new cements to high temperatures must be evaluated, along with the effect of short periods of exposure (the time needed to extinguish a standard fire) on their mechanical properties.

This study attempts to respond to both issues: the lower emission of pollutants into the atmosphere and the higher fire resistance of construction materials. Both issues provide support for the competitiveness of a new generation of alkaline cements as a base material for construction. Along those lines, the present study focuses on a comparative study of the hightemperature performance of a traditional Portland cement and a new cement resulting from the alkali activation of fly ash from coal-fired steam power plants. ${ }^{2-4}$ 


\section{Experimental Procedure}

\section{(1) Starting Material}

A type F fly ash from Puente Nuevo, Spain, steam power plant and a type CEM I $52.5 \mathrm{~N} / \mathrm{SR}$ commercial cement were used in the present study. The chemical composition of these two raw materials and their specific surface as determined with the Blaine method are given in Table I. In addition, the fly ash was likewise characterized by a vitreous phase content of around $63 \%$ and $45.05 \%$ reactive silica. ${ }^{7,19}$

\section{(2) Paste Preparation}

The Portland cement pastes (hereafter CEM matrix) were prepared with a water/cement ratio of 0.27 , by mass (this ratio was determined through the consistency test according to the standard EN 196-3). The pastes obtained were used to make three unlike types of specimens for two different test procedures: (a) Prismatic specimens measuring $8 \times 4 \times 50 \mathrm{~mm}$ and $5 \times 5 \times$ $10 \mathrm{~mm}$ for high-temperature mechanical tests (Test 1) and (b) Prismatic specimens measuring $10 \times 10 \times 60 \mathrm{~mm}$ for the postthermal treatment tests (Test 2) (both tests described below). The curing system was the same for the three types of specimens: $20 \mathrm{~h}$ at ambient temperature in a curing chamber $\left(22 \pm 1{ }^{\circ} \mathrm{C}\right.$, relative humidity $98 \%$ ). After these first $20 \mathrm{~h}$, the specimens were demolded and stored in the curing chamber for 28 days, when the high-temperature stability test was conducted.

The alkaline activator used to prepare the $f$ ly ash pastes (hereafter, the FAN matrix) was an $8 M \mathrm{NaOH}$ solution, and the alkaline solution/ash ratio was 0.25 by mass. The pastes obtained were also used to make three different types of specimens, as above for Test 1 and Test 2. The curing system for the fly ash pastes was different however: the pastes were initially cured for $4 \mathrm{~h}$ at $50^{\circ} \mathrm{C}$ and a relative humidity of $>90 \%$, after which they were demolded and cured for a further $16 \mathrm{~h}$ at $85^{\circ} \mathrm{C}$ and a relative humidity of $>90 \%$. These curing conditions were chosen on the grounds of information extracted from prior studies, ${ }^{6,8}$ which showed the enormous impact of curing temperature on strengthening in these new cements.

\section{(3) Mechanical Characterization}

All the cement paste and fly ash specimens were mechanically characterized to evaluate strength at high temperatures and determine the residual strength after abrupt but not prolonged exposure to high temperatures. Two types of tests were conducted to this end:

(A) High Temperature Mechanical Tests (Test 1): These tests, which were designed to evaluate variations in mechanical performance with temperature, included bending strength $\left(\sigma_{F}\right)$, fracture toughness $\left(\boldsymbol{K}_{\boldsymbol{I C}}\right)$ and compressive strength $\left(\sigma_{C}\right)$.

Bending strength and fracture toughness were determined at temperatures ranging from $25^{\circ}$ to $600^{\circ} \mathrm{C}$ by conducting three-point bending tests on prismatic samples measuring $8 \times 4 \times$ $50 \mathrm{~mm}$, with $40 \mathrm{~mm}$ span between supports. These tests were conducted on an Instron model 4505 servomechanical testing machine, inside which an Entech (Sweden) furnace was installed to conduct the tests at high temperatures. Crosshead displacements during the tests were measured with a linear variable differential transformer (LVDT) strain gauge (resolution $\pm 1 \mu \mathrm{m}$ ) located outside the furnace. The tests were run under displacement control at a loading speed of $50 \mu \mathrm{m} / \mathrm{min}$; the load was applied with high purity alumina $(99.7 \%)$ bars and cylinders. The specimens were heated at a rate of $4{ }^{\circ} \mathrm{C} / \mathrm{min}$ (to prevent the appearance of thermal gradients that might cause premature failure). Once the target temperature was reached, the specimen was stabilized for $20 \mathrm{~min}$ before conducting the test. A diamond saw was used to groove the failure specimens, with notches that were 0.2 times the depth of the specimen and had a bottom radius of $200 \mu \mathrm{m}$.

The compressive mechanical tests were conducted on $5 \times 5 \times 10 \mathrm{~mm}$ specimens in an Instron 8505 servomechanical device testing machine, with an MTS (USA) furnace installed inside its frame. The tests were conducted under displacement control at a loading speed of $200 \mu \mathrm{m} / \mathrm{min}$. Crosshead displacements during the tests were measured with an LVDT strain gauge (resolution $\pm 1 \mu \mathrm{m}$ ) located outside the furnace. In this case the specimens were heated at a rate of $4{ }^{\circ} \mathrm{C} / \mathrm{min}$ to the test temperature $\left(100^{\circ}, 200,{ }^{\circ} 400^{\circ}, 600^{\circ}, 800^{\circ}\right.$, and $\left.1000^{\circ} \mathrm{C}\right)$, after which the specimen was stabilized for $20 \mathrm{~min}$ before proceeding to run the test.

In all cases, the specimens were subjected to a $5 \mathrm{~N}$ preload during heating to fasten them securely to the testing device. At high temperatures, this caused very pronounced deformation before failure, which occurred at very low loads, or spontaneous specimen failure during heating due to the deterioration of its properties at high temperatures. These incidents determined the maximum characterization temperature for each material.

Three-point bending strength was determined by applying Bernoulli's theory, ${ }^{20}$ while design failure was calculated from the general equation for notched beams proposed by Guinea et al. ${ }^{21}$ In addition, the fracture surfaces of the samples tested were examined under a JELO JSM 6300 scanning electron microscope.

(B) Post-Thermal Mechanical Tests (Test 2): Here the intention was to evaluate the residual strength after abrupt but not prolonged exposure to high temperatures, in an attempt to simulate the conditions prevailing in the event of accidental fire. Specimens measuring $10 \times 10 \times 60 \mathrm{~mm}$ were subjected to strong thermal shock by placing them directly inside a furnace at different temperatures $\left(200^{\circ}, 400^{\circ}, 600^{\circ}, 800^{\circ}\right.$ and $\left.1000^{\circ} \mathrm{C}\right)$. They were subsequently kept in this high-temperature environment for $1 \mathrm{~h}$ (mean time estimated to be needed to extinguish the hot spot in a fire). Finally, the samples were withdrawn from the furnace and subjected to a second thermal shock, consisting in an abrupt cooling to ambient temperature in air.

Subsequently, the tempered specimens were tested for residual bending $\left(\sigma_{\boldsymbol{F R}}\right)$ and compressive strength $\left(\sigma_{\boldsymbol{C R}}\right)$ at ambient temperature. Three-point bending failure tests were conducted on prismatic specimens measuring $10 \times 10 \times 60 \mathrm{~mm}$ in a Netzsch 401-2 constant loading speed device, with the supports spaced at $20.50 \mathrm{~mm}$. Each strength value was the mean for six specimens tested to failure under identical conditions. Compressive mechanical tests were conducted on both halves of the specimens broken in the bending test. The device used in this case was an Ibertest Autotest-200/10-SW hydraulic machine (Spain), set at a loading rate of $0.07 \mathrm{kN} / \mathrm{s}$.

In addition, the starting materials as well as the samples tested under the two conditions were analyzed using DTG/TG, XRD and FTIR. A Labsys SETARAM facility was used for combined thermogravimetric-differential thermal analysis (TG/DTA). Samples were heated from $100^{\circ}$ to $1050^{\circ} \mathrm{C}$ at a rate of $4^{\circ} \mathrm{C} / \mathrm{min}$ in air. The diffractometer used was a Philips PW $1730\left(\mathrm{Cu} K \alpha\right.$ radiation). Samples were examined in the $5^{\circ}-60^{\circ} 2 \theta$ range at a scanning rate of $2^{\circ} / \mathrm{min}$. An ATI Mattson FTIR-TM series infrared radiation spectrometer was used. The samples were prepared for FTIR analysis in the form of $\mathrm{KBr}$ pellets. Analyses were conducted in the spectral range between 400 and

Table I. Chemical Composition of the Raw Materials

\begin{tabular}{|c|c|c|c|c|c|c|c|c|c|c|c|}
\hline & LOI & $\mathrm{SiO}_{2}$ & $\mathrm{Al}_{2} \mathrm{O}_{3}$ & $\mathrm{Fe}_{2} \mathrm{O}_{3}$ & $\mathrm{MgO}$ & $\mathrm{CaO}$ & $\mathrm{SO}_{3}$ & $\mathrm{Na}_{2} \mathrm{O}$ & $\mathrm{K}_{2} \mathrm{O}$ & IR & Blaine $\left(\mathrm{m}^{2} / \mathrm{kg}\right)$ \\
\hline Ash & 2.19 & 54.42 & 26.42 & 7.01 & 1.79 & 3.21 & 0.01 & 0.59 & 3.02 & 0.78 & 202 \\
\hline Cement & 2.55 & 20.06 & 6.18 & 2.26 & 0.18 & 62.50 & 2.81 & 0.27 & 0.73 & 0.74 & 398 \\
\hline
\end{tabular}

LOI $=$ Loss on ignition $\left(1000^{\circ} \mathrm{C}\right) ; \mathrm{RI}=$ Insoluble residue. 

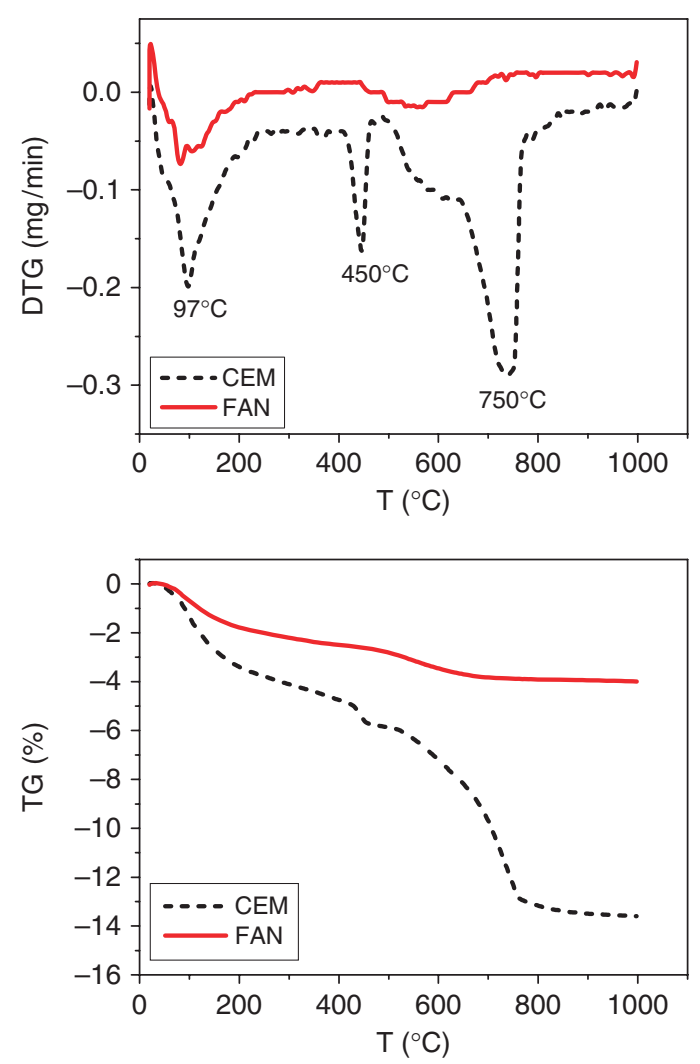

Fig. 1. TG and DTG curves for the untested CEM and FAN samples.

$1600 \mathrm{~cm}^{-1}$ at a resolution of $4 \mathrm{~cm}^{-1}$. See Guinea et al. ${ }^{21}$ and Fernández-Jimenez et al. ${ }^{22,23}$ for further details.

\section{Results and Discussion}

The thermogravimetric (TG/DTG) results obtained for the working materials are given in Fig. 1. The DTG curve for Portland cement pastes had three peaks, at around $97^{\circ}, 450^{\circ}$, and $750^{\circ} \mathrm{C}$. The first was associated with the loss of adsorbed water and $\mathrm{C}-\mathrm{S}-\mathrm{H}$ gel decomposition, while the other two were attributed to the decomposition of portlandite and $\mathrm{CaCO}_{3}$, respectively. ${ }^{24-26}$ As the TG curve in Fig. 1 shows, these transformations involved weight loss. The high level of weight loss

(a)

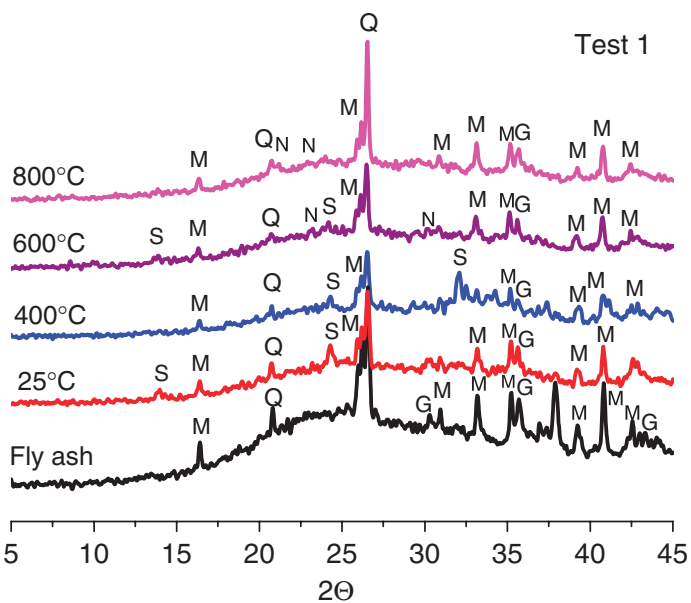

observed at temperatures higher than $600^{\circ} \mathrm{C}$ could be associated to the high carbonation observed by XRD (data not included in the paper) in the OPC sample.

While the DTG curve for the alkali-activated fly ash pastes also had one wide peak at around $100^{\circ} \mathrm{C}$, it was less intense than the analogous Portland cement signal. Like in the case of the Portland cement, this peak was associated with the loss of adsorbed and combined water in the N-A-S-H gel. ${ }^{27,28}$ The broad shoulder between $500^{\circ}$ and $700^{\circ} \mathrm{C}$ on this curve would appear to mean that transformations were taking place in this range, although the loss of mass was fairly moderate (see TG curve). Indeed, a comparison of the TG curves for the two materials, CEM and FAN, showed that the weight losses were visibly lower in the activated fly ash than in the Portland cement pastes. The implication is that the former material does not readily decompose when exposed to high temperatures, under which conditions it would appear to be more structurally stable than Portland cement.

XRD and FTIR techniques were used to acquire a better understanding of the possible transformations underway in the original material as well as in the samples subjected to high temperature mechanical tests (Test 1 ) and post-thermal treatment tests (Test 2) as a result of exposure to high temperatures. Because cement matrix behaviour at high temperatures has been widely studied by many authors and is well understood, ${ }^{26,29,30}$ the present analysis focused on the description and interpretation of the changes observed in the mineralogy and microstructure of materials made with alkali activated fly ash (FAN).

Figure 2 shows the diffractograms for the original fly ash and the FAN matrix after the high-temperature tests. The minority crystalline phases present in the initial ash (quartz and mullite) were scantly affected by the activation process or exposure to high temperatures. At the same time, the characteristic halo of the vitreous phase in the initial ash (located in the $20^{\circ}-30^{\circ} 2 \theta$ range) shifted to $2 \theta$ values of $25^{\circ}-35^{\circ}$ as a result of alkaline activation (see Fig. $2,25^{\circ} \mathrm{C}$ spectrum). This shift is indicative of the formation of an alkaline aluminosilicate gel (N-A-S-H) as the main reaction product, which may be a determining factor in temperature-induced strength loss. ${ }^{4,22,23}$ Slight changes in intensity are observed in this halo with rising temperature but are difficult to quantify.

Zeolites formed as secondary reaction products. Hydroxysodalite $\left(\mathrm{Na}_{4} \mathrm{Al}_{3} \mathrm{Si}_{3} \mathrm{O}_{12} \mathrm{OH}\right)$ formed in the initial FAN matrix as a minority crystalline phase during activation. In a sufficiently alkaline medium, hydroxysodalite is so thermodynamically stable that it crystallizes fairly quickly and easily. ${ }^{28,31,32}$ Moreover, this zeolite, found relatively frequently in alkali activated fly ash cementitious systems, ${ }^{22,23}$ maintains its thermal stability

(b)

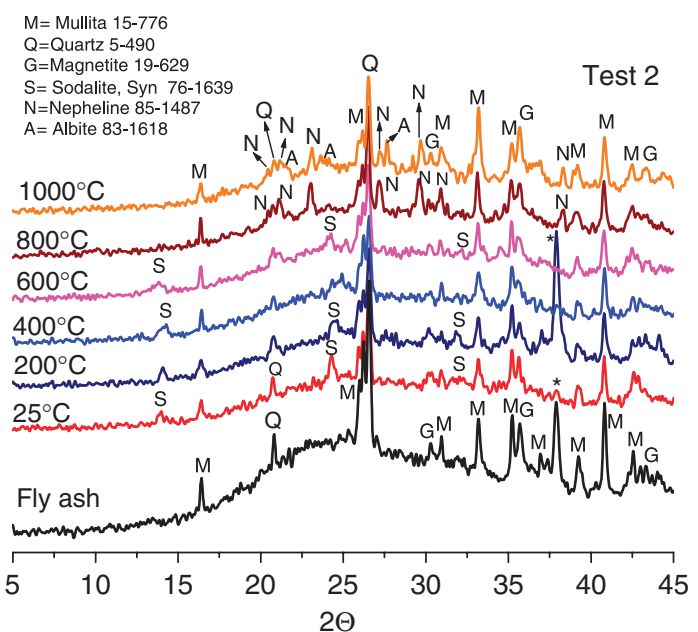

Fig. 2. Diffractogram for the FAN sample. (a) High temperature mechanical tests (Test 1); (b) post-thermal treatment test samples (Test 2). In both cases, the results are compared with the initial fly ash (fly ash) and a sample tested at ambient temperature (FAN). 
(a)

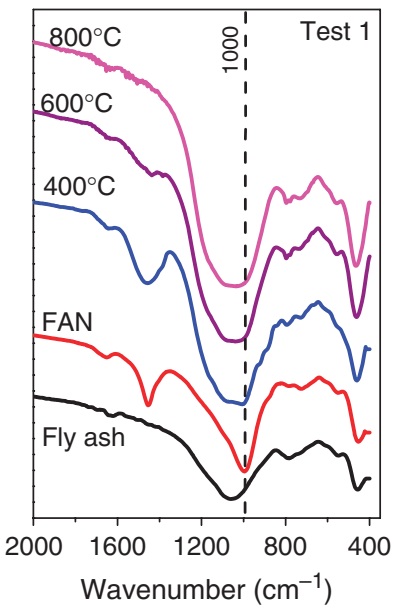

(b)

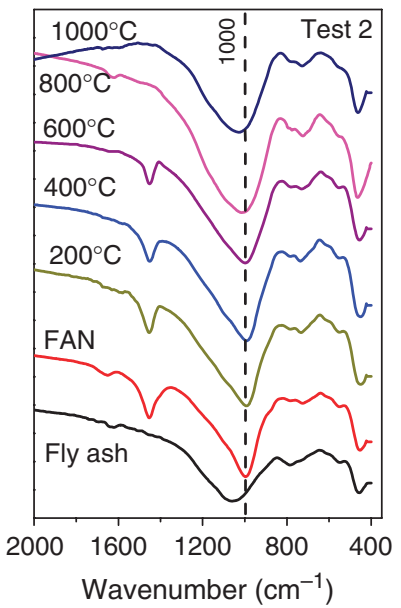

Fig. 3. FTIR spectra: (a) high temperature mechanical tests (Test 1); (b) post-thermal treatment test samples (Test 2). In both cases, the results are compared to the initial fly ash (fly ash) and a sample tested at ambient temperature (FAN).

up to $600^{\circ} \mathrm{C}$. It is also characterized by a propensity to undergo minor dehydration and recrystallization as nepheline, albite, or other stable anhydrous aluminosilicates. Its aluminosilicate structure, which helps maintain the dimensional stability of the material, ${ }^{32}$ is unaffected by these changes.

In this specific case, hydroxysodalite was observed to disappear and nepheline $\left(\mathrm{NaAlSiO}_{4}\right)$ to form at temperatures of over $600^{\circ} \mathrm{C}$. Nepheline is a feldspar that nucleates at high temperatures and closely resembles sodalite in terms of chemical composition, both having a $\mathrm{Si} / \mathrm{Al}$ ratio $=1.0$. The temperature at which this phase appeared concurred with the shoulder at $500^{\circ}-700^{\circ} \mathrm{C}$ observed on the DTG curve (Fig. 1). Finally, at $1000^{\circ} \mathrm{C}$, the presence of small quantities of albite $\left(\mathrm{NaAlSi}_{3} \mathrm{O}_{8}\right)$ was detected in addition to nepheline (see the diffractograms in Fig. 2). As a rule, these transformations involve intermediate sintering and the concomitant formation of a vitreous phase. $^{28,31,32}$

The diffractograms for the materials tested during and after heating at different temperatures (Tests 1 and 2) were found to be similar, inasmuch as the same zeolites, namely sodalite and nepheline, formed as minority phases. Nonetheless, the intensity of these zeolite peaks was considerably lower in the Test 1 patterns, in which the exposure time to high temperatures was substantially shorter.

Figure 3 shows the FTIR spectra for both the original materials and the specimens tested at high temperatures. The band associated with the $\mathrm{T}-\mathrm{O}$ bond asymmetric stretching vibrations $\left(\mathrm{T}=\mathrm{Si}\right.$ and/or $\mathrm{Al}$, band $\left.\mathrm{v}_{3}\right)$, which in the initial

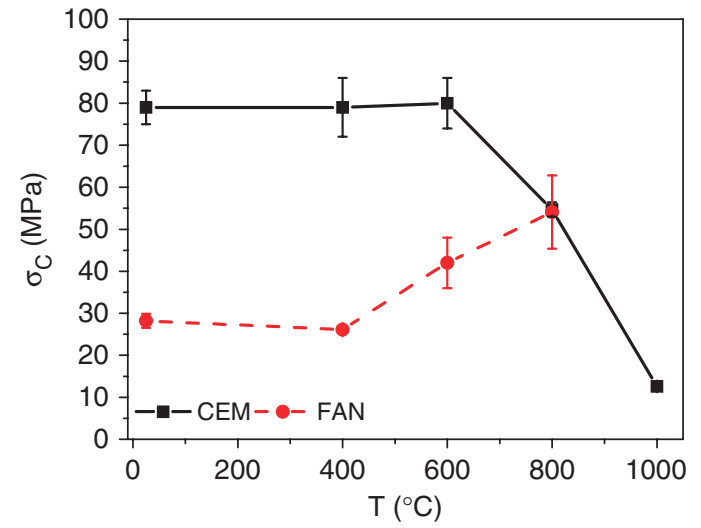

Fig. 5. Compressive strength versus temperature (Test 1).

ash appeared at $1088 \mathrm{~cm}^{-1}$, was found to grow progressively narrower and shift to longer wavelengths $\left(927 \mathrm{~cm}^{-1}\right.$, FAN spectrum) as a result of alkaline activation. This corroborated the finding reported earlier ${ }^{23}$ that most of the vitreous phase in the ash dissolved in the alkaline medium and subsequently precipitated in the form of a sodium aluminosilicate gel (N-A-S-H gel).

When this material, FAN, was exposed to high temperatures $\left(200^{\circ}, 400^{\circ}\right.$ and $\left.600^{\circ} \mathrm{C}\right)$ and later cooled, this band exhibited only slight positional variations $\left(993,991\right.$ and $997 \mathrm{~cm}^{-1}$, respectively). At temperatures of over $600^{\circ} \mathrm{C}$, however, the band widened and shifted to shorter wavelengths $\left(1012\right.$ and $1028 \mathrm{~cm}^{-1}$ at $800^{\circ}$ and $1000^{\circ} \mathrm{C}$, respectively). These data concurred with the information obtained from DTG and TG analysis, according to which after $600^{\circ} \mathrm{C}$ the FAN materials underwent partial sintering followed by vitrification as a result of abrupt cooling to ambient temperature. This series of events may have been the cause of the increase in the structural disorder of the material and the appearance of very wide $\mathrm{T}-\mathrm{O}$ bond vibration bands on the IR spectrum.

As in the case of the XRD patterns, the FTIR spectra for the Test 1 materials were less sharply defined, confirming that the materials were less crystalline.

Figures 4 and 5 show bending and compressive strength versus temperature (Test 1 ) for the two materials.

The Portland cement control sample exhibited high bending and compressive strength at ambient temperature, probably due to a good cement quality, a low water/cement ratio and a high carbonation level too. This material undergoes a significant reduction of bending strength up to $400^{\circ} \mathrm{C}$ due to the loss of combined water leading to a reduction of the $\mathrm{Ca}(\mathrm{OH})_{2}$ content. The descent in the average compressive strength with temperature shows distinct distress beyond $600^{\circ} \mathrm{C}$. Similar pattern of reduction in strength of concrete specimens had already been

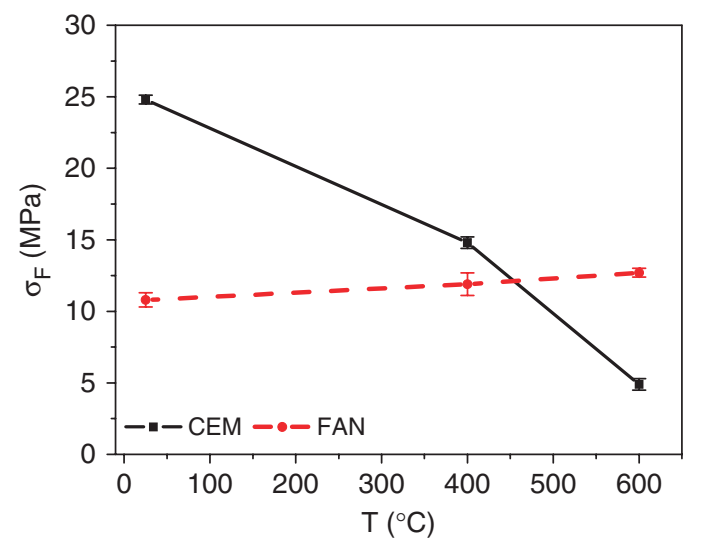

Fig. 4. Bending strength versus temperature (Test 1).

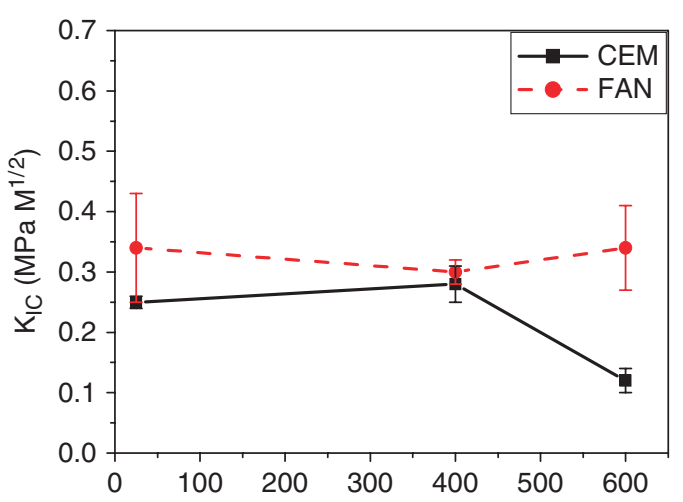

Fig. 6. Fracture toughness verisus temperature (Test 1). 


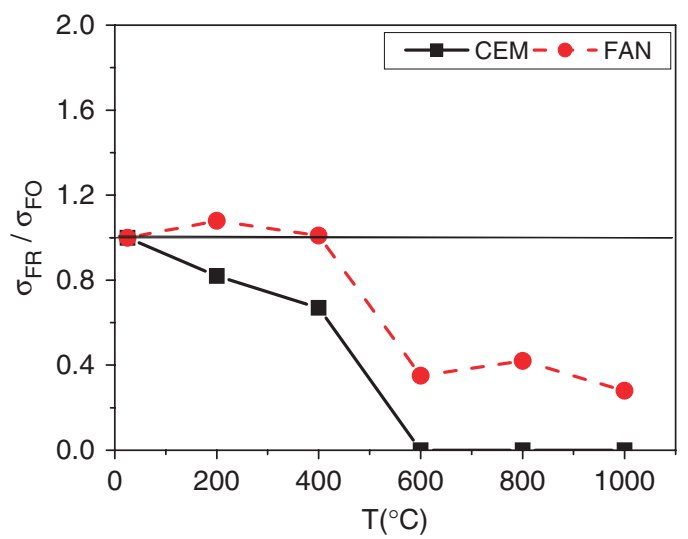

Fig. 7. Variation in residual bending strength during the post-thermal treatment test after $1 \mathrm{~h}$ at different temperatures (Test 2).

reported earlier. ${ }^{24,25,29}$ In any case this decline was more visible and occurred at lower temperatures in the bending test for its greater sensitivity to the presence of flaws or damage induced in the material (changes in the morphology and microcracks formation).

By contrast, the bending strength of the cement obtained from activated ash barely changed with temperature (and in fact rose slightly) and its compressive strength, surprisingly, climbed considerably at temperatures of over $400^{\circ} \mathrm{C}$.

Figure 6 shows the fracture toughness results for the two materials at different temperatures. Both cements were observed to have similar toughness values at ambient temperature, whereas for the control cement, CEM, toughness fell at temperatures of over $400^{\circ} \mathrm{C}$, declining to slightly over half of the initial values at $600^{\circ} \mathrm{C}$, in the activated ash it remained unchanged up to a temperature of $600^{\circ} \mathrm{C}$.

Figures 7 and 8 show the variation in the residual values for bending $\left(\sigma_{\mathrm{FR}}\right)$ and compressive strength $\left(\sigma_{\mathrm{CR}}\right)$, standardized to the respective bending $\left(\sigma_{\mathrm{F} 0}\right)$ and compressive strength $\left(\sigma_{\mathrm{CO}}\right)$ values at ambient temperature to illustrate more clearly the deterioration of the material after exposure to high temperatures.

As Fig. 7 shows, residual Portland cement bending strength declined steadily as the temperature rose. A dip of $33 \%$ was recorded at $400^{\circ} \mathrm{C}$. At temperatures upward of $600^{\circ} \mathrm{C}$ this cement had practically negligible residual bending strength. In the fly ash cement, on the contrary, the residual bending strength remained constant to $400^{\circ} \mathrm{C}$, falling to one-third of the initial value at higher temperatures. This value remained steady up to $1000^{\circ} \mathrm{C}$, however, and was much higher than the figure recorded for conventional cement.

Fig. 8 shows that the residual compressive strength in the Portland cement control declined with rising temperatures, to values close to zero for temperatures over $800^{\circ} \mathrm{C}$. This behaviour

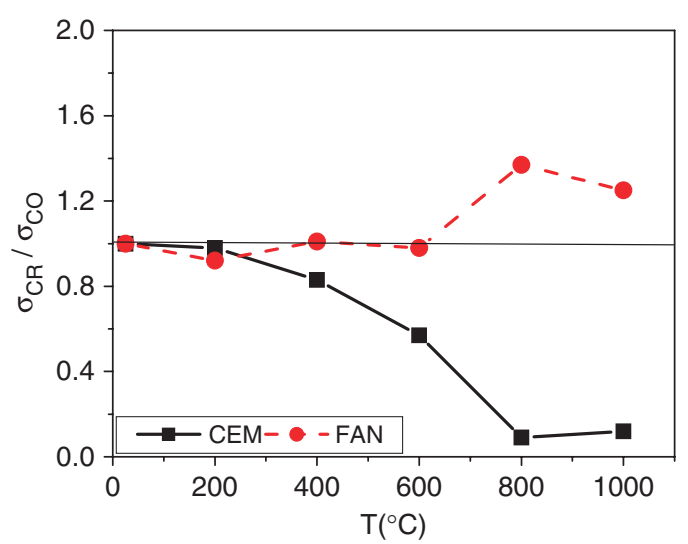

Fig. 8. Variation in residual compressive strength during the post-thermal treatment test after $1 \mathrm{~h}$ at different temperatures (Test 2). (a)

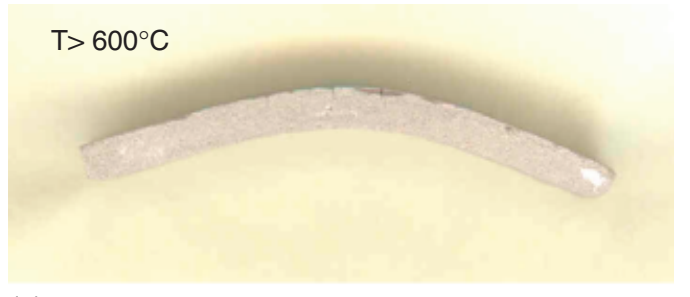

(b)

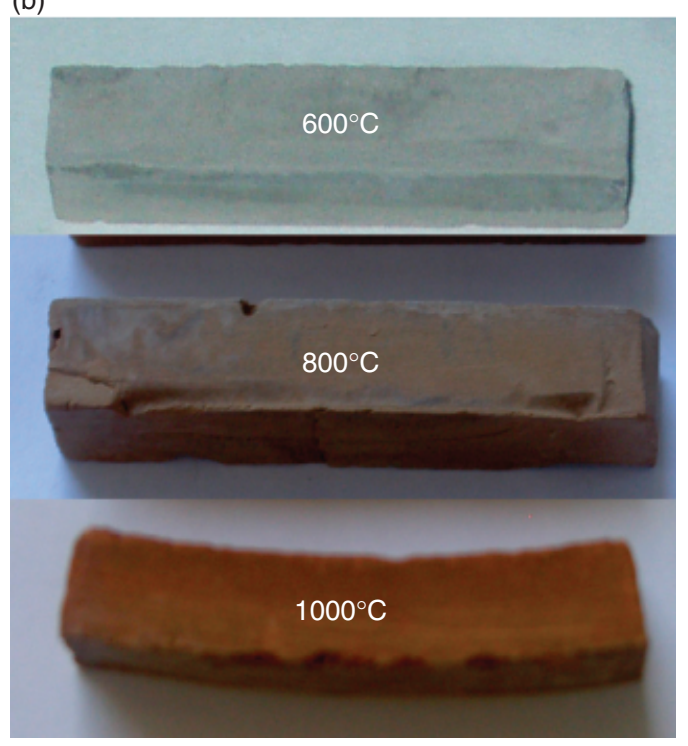

Fig. 9. Physical appearance of the FAN material after thermal treatment: (a) under a 5-N load at temperatures of over $600^{\circ} \mathrm{C}$ and (b) pursuant to Test 2.

contrasts with the findings for the activated ash material, where residual compressive strength was practically constant (with a slight increase between $800^{\circ}$ and $1000^{\circ} \mathrm{C}$ ) regardless of the thermal treatment temperature.

The endothermal shoulder between $500^{\circ}$ and $700^{\circ} \mathrm{C}$ on the DTG curve in Fig. 1 is followed by a low intensity peak attributed to a microstructural transformation. That transformation may have been responsible for the decline in the mechanical performance of the FAN cement at temperatures of over $600^{\circ} \mathrm{C}$, for, as noted above, it is generally associated with the formation of a sintering phase that gives rise to viscous vitreous phases.

This vitreous phase would be responsible for the plastic behaviour observed in Fig. 9, possibly giving rise to local plastic behaviour that would initially lead to the sealing of cracks and pores. Both the unreacted fly ash particles and the zeolite crystals formed would become embedded in the resulting matrix, which would be more compact. That in turn would increase the specific surface of the material able to transmit loads. Consequently, despite a possible dip in intrinsic strength, macroscopic strength would grow as a result of this increase in area; i.e., $\sigma_{\mathrm{C}}$ would rise. These events also explain the higher toughness and strength observed at temperatures of over $500^{\circ}-600^{\circ} \mathrm{C}$, for the material would be more compact and the size of its flaws smaller. At the same time, these processes would account for the speedy deterioration of the material upward of $600^{\circ} \mathrm{C}$, with the spread of plasticity throughout the specimen, which would therefore exhibit deformation even under very light loads.

Conversely, the TG curve (Fig. 1) shows that temperatureinduced weight loss was substantially smaller in alkali-activated ash than Portland cement specimens. This difference was particularly visible at temperatures of over $450^{\circ} \mathrm{C}$, indicating that the former material does not readily decompose when exposed to high temperatures and would appear to be more structurally stable under such conditions than Portland cement. ${ }^{27}$ This may be the key to explaining the differential behaviour observed in the two materials at high temperatures. While in Portland 


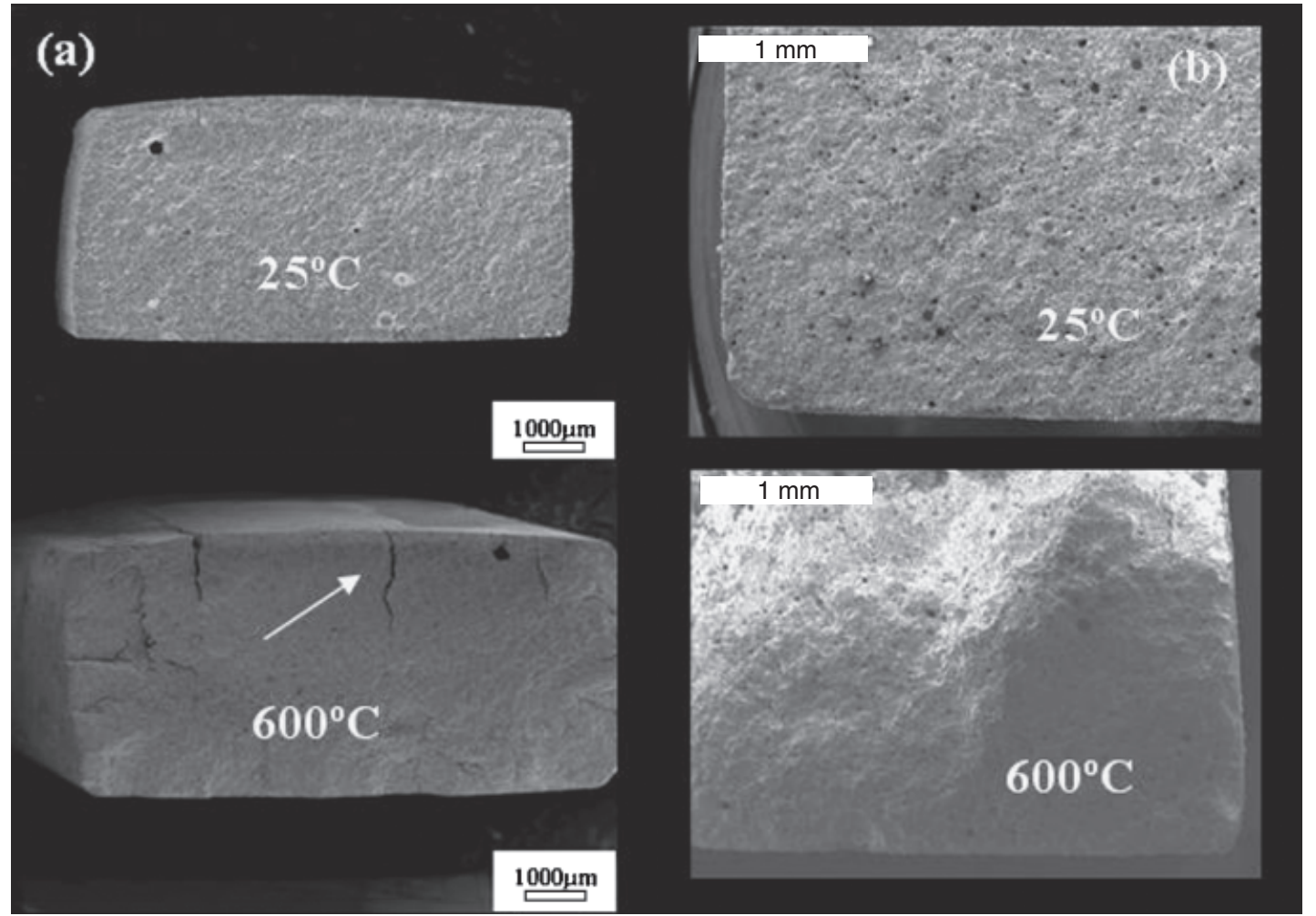

Fig. 10. Physical appearance of the failure surface at $25^{\circ}$ and $600^{\circ} \mathrm{C}$ in Test 1 for (a) cement (CEM system) and (b) ash (FAN system) specimens.

cement mechanical performance declines rapidly at high temperatures due to the deterioration of the material (as shown in Fig. 1), the fly ash material retains its mechanical properties up to $600^{\circ} \mathrm{C}$ because its structural deterioration is much less intense, enabling it to maintain its microstructural integrity at higher temperatures.

Figure 10 compares the appearance of the failure surfaces (Test 1 ) in the Portland cement and alkali activated fly ash specimens at ambient temperature and at $600^{\circ} \mathrm{C}$. At $600^{\circ} \mathrm{C}$ the Portland cement specimens (whose strength declined abruptly with rising temperatures, in both Test 1 and Test 2) showed macroscopic cracks and fragments of material were even found in the furnace. This, together with the data deduced from Fig. 1, explains the speedy deterioration of its strength at over $400^{\circ} \mathrm{C}$.

\section{Conclusions}

Two different types of mechanical test have been used in this investigation in order to demonstrate that the mechanical performance of the cement produced through the alkali activation of fly ashes remains unchanged or even improves between $25^{\circ}$ and $600^{\circ} \mathrm{C}$, while commercial Portland cement performance rapidly declines in that same interval.

Test 1, which was utilized for the first time with alkali activated fly ashes in this research, has evidenced that these new cementitious materials can achieve same local plasticity (flexibility) when submitted to temperatures above $500^{\circ} \mathrm{C}$. This particular characteristic confirms the fact that a melted phasecomponent is forming part of the bulk material at high temperatures. The solidification of that melted phase during the cooling process may explain the excellent mechanical performance of thermally treated alkali activated fly ashes provided by test number two.

\section{Acknowledgments}

The authors wish to thank J. L. Garcia and A. Gil for their assistance with the mechanical tests.

\section{References}

${ }^{1}$ K. L. Scrivener and R. J. Kirkpatrick, "Innovation in Use and Research on Cementitious Material," 12th International Congress of Chemistry of Cement, Montreal, Canada, 2007.

${ }^{2}$ C. Shi, D. Roy, and P. Krivenko, Alkali-Activated Cements and Concrete. Taylor \& Francis, London, 2006, ISBN = 10: 0-415-70004-3.

${ }^{3}$ P. V. Krivenko, Alkaline Cements. Proceedings of the First International Conference of Alkaline Cements and Concretes, pp. 11-129. Vipol Publishers, Kiev, (1994).

${ }^{4}$ P. Duxson, A. Fernández-Jiménez, J. L. Provis, G. C. Lukey, A. Palomo, and J. S. J. van Deventer, "Geopolymer Technology: The Current State of the Art," J. Mater. Sci., 42, 2917-33 (2007).

${ }^{5}$ A. Palomo and G. Glasser, "Chemical-Bonded Cementitious Materials Based on Metakaolin," Br. Ceram. Trans. J., 91 [4] 107-12 (1992).

${ }^{6}$ A. Palomo, S. Alonso, A. Fernández-Jiménez, I. Sobrados, and J. Sanz, "Alkaline Activation of Fly Ashes: NMR Study of the Reaction Products," $J$ Am. Ceram. Soc., 87 [6] 1141-5 (2004).

${ }^{7}$ A. Fernández-Jiménez, A. Palomo, I. Sobrados, and J. Sanz, "The Role Played by The Reactive Alumina Content in The Alkaline Activation of Fly Ashes," Microp. Mesop. Mater., 91, 111-9 (2006).

${ }^{8}$ G. Kovalchuk, A. Fernández-Jiménez, and A. Palomo, "Alkali-Activated Fly Ash: Effect of Thermal Curing Conditions on Mechanical and Microstructural Development-Part II," Fuel, 86, 315-22 (2007).

${ }^{9}$ P. Duxson, J. L. Provis, G. C. Lukey, S. W. Mallicoat, W. M. Kriven, and J. S. J. van Deventer, "Understanding The Relationship between Geopolymer Composition, Microstructure and Mechanical Properties," Coll. Surf. A, 269, 4758 (2005).

${ }^{10}$ A. Fernández-Jiménez, I. García-Lodeiro, and A. Palomo, "Durable Characteristics of Alkali Activated Fly Ashes," J. Mater. Sci., 42, 3055-65 (2007).

${ }^{11}$ I. García-Lodeiro, A. Palomo, and A. Fernández-Jiménez, "The AlkaliAggregate Reaction in Alkali Activated Fly Ash Mortars," Cement Concr. Res., 37, 175-83 (2007).

${ }^{12}$ A. Fernández-Jiménez, A. Palomo, and C. López-Hombrados, "Some Engineering Properties of Alkali Activated Fly Ash Concrete," ACI Mater J., 103 [2] 106-12 (2006).

${ }^{13} \mathrm{C}$. Shi and A. Fernández-Jiménez, "Stabilization/Solidification of Hazardous and Radioactive Wastes with Alkali-Activated Cements," J. Hazard. Mater., 11, 1656-63 (2006).

${ }^{14}$ A. Palomo and J. I. Lopez de la Fuente, "Alkali Activated Cementitious Materials: Alternative Matrices for The Immobilisation of Hazardous Wastes. Part I: Stabilisation of Boron," Cem. Concr. Res., 33/2, 281-8 (2003).

${ }^{15}$ J. G. S. van Jaarsveld, J. S. J. van Deventer, and L. Lorenzen, "The Potential Use of Geopolymeric Materials to Immobilise Toxic Metals, Part I. Theory and Applications," Mineral. Eng., 10, 659-69 (1997).

${ }^{16} \mathrm{~A}$. Palomo and M. Palacios, "Alkali-Activated Cementitious Materials: Alternative Matrices for the Immobilisation of Hazardous Wastes-Part II. Stabilisation of Chromium and Lead," Cem. Concr. Res., 33 [2] 289-95 (2003). 
${ }^{17}$ A. Fernandez-Jimenez, A. Palomo, A. D. E. Macphee, and E. E. Lachowski, "Fixing Arsenic in Alkali-Activated Cementitious Matrices," J. Am. Ceram. Soc., 88 [5] 1122-6 (2005).

${ }^{18}$ D. M. Bastidas, A. Fernández-Jiménez, A. Palomo, and J. A. González, "A Study on The Passive State Stability of Steel Embedded in Activated Fly Ash Mortars," Corr. Sci., 50 [4] 1058-65 (2008).

${ }^{19}$ A. Fernández-Jiménez and A. Palomo, "Characterisation of Fly Ashes. Potential Reactivity as Alkaline Cements," Fuel, 82, 2259-65 (2003).

${ }^{20}$ S. P. Thimoshenko, Strength of Materials, 3rd ed, part II, p.169, D. Van. Nostrand Company Inc., Princeton, NJ, 1956.

${ }^{21}$ G. V. Guinea, J. Y. Pastor, J. Planas, and M. Elices, "Stress Intensity Factor, Compliance and CMOD for General Three-Point-Bend Beam," Int. J. Fract., 89, 103-16 (1998).

${ }^{22}$ A. Fernández-Jimenez, A. G. de la Torre, A. Palomo, G. López-Olmo, M. M. Alonso, and M. A. G. Aranda, "Quantitative Determination of Phases in Alkaline Activation of Fly Ashes. Part II The Degree of Reaction," Fuel, 85, 1960-9 (2006).

${ }^{23}$ A. Fernández-Jiménez and A. Palomo, "Mid-infrared spectroscopic studies of alkali-activated fly ash structure," Microporous. Mesoporous Mater., 86, 207-14 (2005).

${ }^{24}$ H. F. W. Taylor, Cement Chemistry, 134, 2nd ed, Thomas, Telford, 1997.

${ }^{25}$ F. Lea, Lea's Chemistry of Cement and Concrete, 4th ed, Arnold, London, 1998.
${ }^{26}$ E. T. Stepkowska, J. M. Blanes, F. Franco, C. Real, and J. L. Pérez-Rodriguez, "Phase Transformation on Heating of an Aged Cement Paste," Thermochim. Acta, 420, 79-87 (2004).

${ }^{27}$ A. Palomo, A. Macias, M. T. Blanco-Varela, and F. Puertas, "Physical, Chemical and Mechanical Characterization of Geopolymers"; 9th International Congress on the Chemical of Cement New Delhi, India, Vol. 5, pp. 505-11, 1992.

${ }^{28}$ S. Chandrasekhar and P. N. Pramada, "Sintering Behaviour of Calcium Exchanged Low Silica Zeolites Synthesized from Kaolin," Ceram. Int., 27, 105 14 (2001).

${ }^{29}$ S. K. Handoo, S. Agarwal, and S. K. Agarwal, "Physicochemical, Mineralogical Characteristics of Concrete Exposed to Elevated Temperatures," Cem. Concr. Res., 32, 1009-18 (2002).

${ }^{30}$ C. Alonso and L. Fernandez, "Dehydration and Rehydration Processes of Cement Paste Exposed to High Temperature Environments," J. Mater. Sci., 39, 3015-24.

${ }^{31}$ R. Dimitrijevic, V. Dondur, P. Vulic, S. Markovic, and S. Macura, "Structural Characterization of Pure Na-Nephelines Synthesized by Zeolite Conversion Route," J. Phys. Chem. Solids, 65, 1623-33 (2004).

${ }^{32}$ P. V. Krivenko and G. Y. Kovalchuk, "Directed Synthesis of Alkaline Aluminosilicate Minerals in a Geocement Matrix," J. Mater Sci., 42, 2944-52 (2007). 